\title{
Label-free Electrochemical Sensor for MicroRNA Detection based on a Gold Nanoparticles@Poly(methylene blue)-Modified Electrode and a Target Cyclic Amplification Strategy
}

\author{
Weiwei Wang \\ Institution of Biology and Food Engineering, Suzhou University, Suzhou 234000, China \\ E-mail: 249432388@qq.com
}

doi: $10.20964 / 2020.05 .30$

Received: 30 December 2019 / Accepted: 22 February 2020 / Published: 10 April 2020

\begin{abstract}
Herein, a gold nanoparticles (AuNPs)/poly(methylene blue) (PMB)-modified electrode was fabricated and employed to sensitively detect microRNA (miRNA). A PMB film was electropolymerized onto the surface of a glass carbon electrode (GCE). AuNPs were immobilized onto the PMB/GCE surface, which provided a platform for the immobilization of probe DNA (pDNA) via Au-S bonds. In our strategy, when target miRNA was present, a target cyclic amplification reaction was triggered, which resulted in an electrochemical behaviour change at the PMB-solution interface. The signal change, which resulted from DNA hybridization generated on the electrode surface, was used to detect target miRNA with differential pulse voltammetry (DPV). The experimental results showed that the proposed sensor could detect miRNA-21 with high sensitivity and selectivity. The DPV peak current change $(\triangle I)$ showed a good linear relationship with the logarithm of concentration in a range of $1.0 \times 10^{-13}-1.0 \times 10^{-9} \mathrm{~mol} / \mathrm{L}$, and the detection limit was $3.0 \times 10^{-14} \mathrm{~mol} / \mathrm{L}(S / N=3)$. In addition, the sensor had good stability and reproducibility. Thus, the as-produced sensor has good application prospects in miRNA analysis.
\end{abstract}

Keywords: Gold nanoparticles; Poly(methylene blue); MicroRNA; Electrochemical sensor; Differential pulse voltammetry

\section{$\underline{\text { FULL TEXT }}$}

(C) 2020 The Authors. Published by ESG (www.electrochemsci.org). This article is an open access article distributed under the terms and conditions of the Creative Commons Attribution license (http://creativecommons.org/licenses/by/4.0/). 